\title{
Thermal Properties of Poly(ethylene 2,6-naphthalate) and Poly(butylene 2,6-naphthalate) Blends
}

\author{
Kwan Han Yoon, ${ }^{\dagger}$ Sang Cheol Lee, and O Ok Park* \\ Department of Polymer Science \& Engineering, Kum-Oh National University of Technology, \\ Kumi City, Kyungbuk 730-701, Korea \\ * Department of Chemical Engineering, Korea Advanced Institute of Science \& Technology, \\ 373-1 Kusung-Dong, Yusung-ku, Taejon 305-701, Korea
}

(Received October 12, 1993)

\begin{abstract}
Thermal properties of poly(ethylene 2,6-naphthalate) (PEN)/poly(butylene 2,6-naphthalate) (PBN) blends were investigated by differential scanning calorimetry. Blends containing less than $60 \mathrm{wt} \% \mathrm{PBN}$ showed double glass transitions, which approach mutually closer with increasing PBN content, whereas a single glass transition was observed for compositions more than $80 \mathrm{wt} \%$ PBN. This behavior indicates that the blends with $60 \mathrm{wt} \% \mathrm{PBN}$ or less separate into two amorphous phases containing both components and the difference in composition between two phases decreases with an increase of PBN content, while a single amorphous phase is formed for compositions more than $80 \mathrm{wt} \% \mathrm{PBN}$. This result was supported by melting behavior and crystallization kinetics.
\end{abstract}

KEY WORDS Miscibility / Poly(ethylene 2,6-naphthalate) / Poly(butylene 2,6-naphthalate) / Crystallization / Transesterification / Blend /

There have been a great interest in blends of polyesters for their growing industrial importance. Many polyesters have been found to be miscible or partially miscible with other polyesters. Among these blends, poly(ethylene terephthalate) (PET)/poly(butylene terephthalate) (PBT) pair is a typical commercialized system. It was reported that PET/PBT blends ${ }^{1}$ are miscible in the amorphous phase by the observation of a single glass transition temperature over the entire composition range. Although many blends of polyesters have been investigated both for industrial application and academic interest, only a few publications ${ }^{2,3}$ are available about blends of polyesters containing naphthalene group as structural unit.

In the present study, we describe the thermal analysis of poly(ethylene 2,6-naphthalate)
(PEN) and poly(butylene 2,6-naphthalate) (PBN) blends. Miscibility of PEN/PBN blends is examined by the observation of glass transition temperatures. The melting behavior and the non-isothermal crystallization kinetics are also discussed in terms of miscibility.

\section{EXPERIMENTAL}

\section{Polymer Preparation}

PEN was prepared by melt polymerization. Dimethyl naphthalate (DMN), which was kindly supplied by Kolon Ind., was reacted with ethylene glycol in the presence of $\mathrm{Mn}(\mathrm{OAc})_{2} \cdot 4 \mathrm{H}_{2} \mathrm{O}$ catalyst in a small scale batch reactor with a nitrogen inlet. The reactor was heated to $230^{\circ} \mathrm{C}$ in a silicone oil bath and this temperature was maintained for $4 \mathrm{~h}$. After that, $\mathrm{Sb}_{2} \mathrm{O}_{3}$ catalyst was introduced into the

\footnotetext{
$\uparrow$ To whom correspondence should be addressed.
} 
reactor and reaction temperature was progressively increased up to $295^{\circ} \mathrm{C}$ and then the pressure was reduced to a specified level. PBN was prepared similarly with different reaction temperatures $\left(190^{\circ} \mathrm{C}\right.$ and $\left.260^{\circ} \mathrm{C}\right)$ and different catalyst (titanium tetrabutoxide) by the reaction of DMN and butylene glycol. The properties of PEN and PBN polymerized are listed in Table I.

\section{Blend Preparation}

The blends were prepared by dissolving two polymers in a mixed solvent of phenol and $o$-dichlorobenzene $(60: 40, \mathrm{v} / \mathrm{v})$. The polymer solutions were then poured into a large excess of acetone. The precipitated polymers were filtered and then dried in a vacuum oven at $150^{\circ} \mathrm{C}$ for $16 \mathrm{~h}$.

\section{Differential Scanning Calorimetry}

Thermal analysis was performed on a du Pont 910 Differential Scanning Calorimeter (DSC) equipped with a mechanical cooling accessory. Samples were first melted at $280^{\circ} \mathrm{C}$ for $5 \mathrm{~min}$, and then quenched into liquid nitrogen. The quenched samples were heated from $-30^{\circ} \mathrm{C}$ to $300^{\circ} \mathrm{C}$ at a heating rate of $20^{\circ} \mathrm{Cmin}^{-1}$ on DSC apparatus to measure glass transition $\left(T_{\mathrm{g}}\right)$ and melting temperature $\left(T_{\mathrm{m}}\right)$. The melting temperatures of isothermally crystallized samples were also measured as follows. Samples were melted at $280^{\circ} \mathrm{C}$ for 5 min, cooled quickly to $235^{\circ} \mathrm{C}$ and maintained at that temperature for $60 \mathrm{~min}$ to permit crystallization of PEN, cooled subsequently to

Table I. Properties of polymers

\begin{tabular}{|c|c|c|c|}
\hline \multirow{2}{*}{ Sample } & $\begin{array}{l}\text { Inherent } \\
\text { viscosity }^{\mathrm{a}}\end{array}$ & $T_{\mathrm{g}}$ & $T_{\mathrm{m}}$ \\
\hline & $\mathrm{dl} \mathrm{g}^{-1}$ & ${ }^{\circ} \mathrm{C}$ & ${ }^{\circ} \mathrm{C}$ \\
\hline PEN & 0.53 & 125 & 268 \\
\hline PBN & 0.83 & 48 & 247 \\
\hline
\end{tabular}

a Values measured with a mixed solvent of phenol-odichlorobenzene $(60: 40, \mathrm{v} / \mathrm{v})$ at $35^{\circ} \mathrm{C}$. $200^{\circ} \mathrm{C}$ and maintained at that temperature for additional $60 \mathrm{~min}$ to allow crystallization of PBN. These samples were then cooled to room temperature and heated to $300^{\circ} \mathrm{C}$ at a heating rate of $20^{\circ} \mathrm{C} \mathrm{min}^{-1}$. For the non-isothermal crystallization kinetics, samples were melted at $280^{\circ} \mathrm{C}$ for $5 \mathrm{~min}$ and then cooled from $280^{\circ} \mathrm{C}$ to $100^{\circ} \mathrm{C}$ at a cooling rate of $10^{\circ} \mathrm{C} \mathrm{min}^{-1}$. The crystallization exotherms recored on cooling were used for the analysis of non-isothermal crystallization kinetics.

\section{RESULTS AND DISCUSSION}

Figure 1 shows the DSC curves obtained on heating the quenched samples. The blends containing more than $80 \mathrm{wt} \%$ PBN show no exothermic peak of cold crystallization, since PBN crystals can be formed fast enough during quenching. On the other hand, for the blends with $60 \mathrm{wt} \%$ PBN or less, a cold crystallization

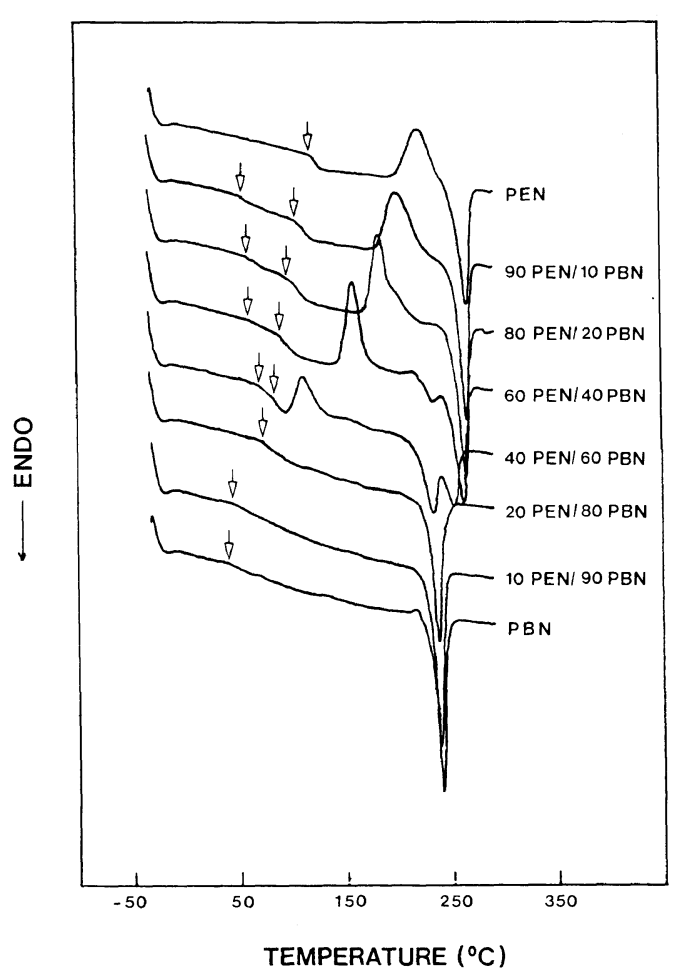

Figure 1. DSC curves of PEN/PBN blends. 


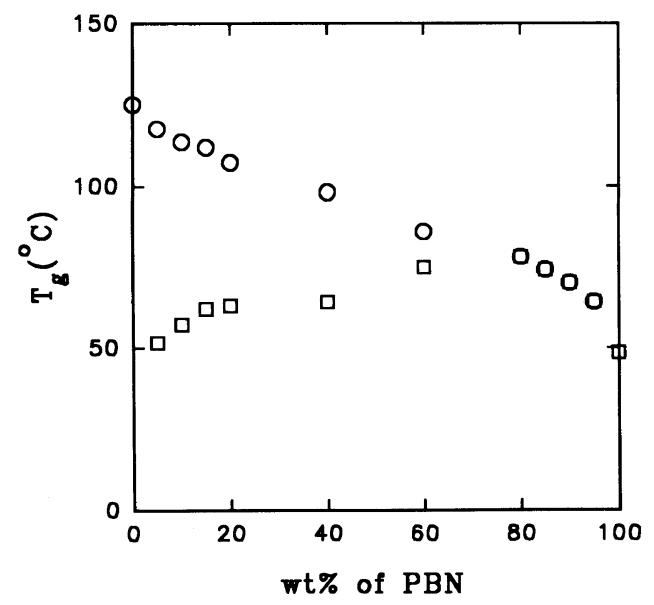

Figure 2. Glass transition temperatures of $\mathrm{PEN} / \mathrm{PBN}$ blends: (O) PEN-rich phase; ( $\square$ ) PBN-rich phase.

exotherm is observed. This exothermic peak is attributed to the crystallization of PEN, because PBN has already crystallized on quenching. The exothermic peak temperature tends to decrease with increasing PBN content, which means that PBN facilitates the crystallization of PEN.

The dependence of the glass transition temperatures (marked by arrows in Figure 1) on blend composition is shown in Figure 2. Blends containing less than $60 \mathrm{wt} \% \mathrm{PBN}$ have double glass transitions, which approach mutually closer with increasing PBN content. For compositions more than $80 \mathrm{wt} \% \mathrm{PBN}$, a single transition is observed. This behavior indicates that the blends with $60 \mathrm{wt} \% \mathrm{PBN}$ or less seperate into two amorphous phases. Perhaps one phase is relatively rich in PEN and the other phase in PBN, i.e., partial miscibility. As the blend content of PBN is increased, the PEN-rich phase seems to incorporate more PBN and the PBN-rich phase also more PEN, which means that the difference in composition between two phases decreases with an increase of PBN content. At the blend composition more than $80 \mathrm{wt} \% \mathrm{PBN}$, the compositions of two phases become identical and a single phase is formed.
Phase behavior, such as miscibility exists over a part of one end of the composition range while at the other end of the range the system seperates into two phases, can be attributed to the dependence of the polymer-polymer interaction parameter on the blend composition. ${ }^{4}$ In the present system, therefore, it is considered that the interaction parameter is negative over the blend composition more than $80 \mathrm{wt} \% \mathrm{PBN}$, but for the other range of composition it is positive. Thermodynamically, when a twocomponent system seperates into two phases at a certain temperature, the relative amounts of two phases change with the mixing composition according to the lever rule, but the composition of each phase is independent of the mixing composition. This thermodynamic rule is not accord with our result that the compositions of PEN-rich and PBN-rich phases depend on the blend composition. Several workers ${ }^{5-7}$ have also reported that the compositions of two coexisting phases vary with the blend composition for some polymer blends. This phenomenon suggests that a polymer-polymer blend can not be regarded as a two-component system. Substantially, a polymer contains a large number of components, which are usually homologues differing in chain length. Koningsveld and coworkers ${ }^{8,9}$ have extensively studied the effect of polydispersity on liquid-liquid phase relationships in multicomponent polymer systems such as solvent-polymer and polymer-polymer, etc. According to their model based on the Flory-Huggins lattice theory, the compositions of two coexisting phases at constant temperature depend on the overall composition because a cloud-point curve is not identified with a coexistence curve. Hence, the change of double glass transitions with blend composition seems to originate from the molecular weight distribution of two polymers.

The melting temperatures are shown in Figure 3. Melting endotherms of PEN and PBN crystals are separately exhibited only for the compositions of $40 \mathrm{wt} \% \mathrm{PBN}$ and $60 \mathrm{wt} \%$ 


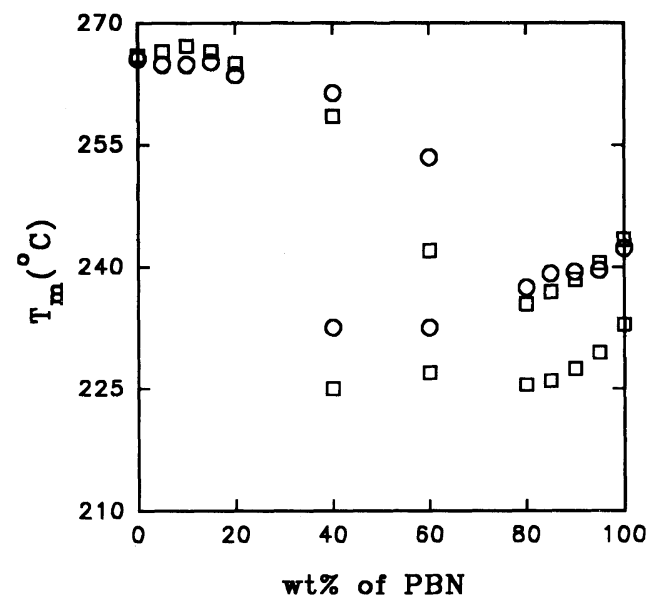

Figure 3. Melting temperatures of PEN/PBN blends: (O) samples quenched from the melt into liquid nitrogen; ( $\square$ ) samples crystallized at $235^{\circ} \mathrm{C}$ for $60 \mathrm{~min}$ and at $200^{\circ} \mathrm{C}$ for additional $60 \mathrm{~min}$.

PBN, while over the other composition range, crystal melting of minor component does not appear on the DSC curve. The isothermally crystallized samples with compositions more than $80 \mathrm{wt} \%$ PBN exhibit double melting peaks of PBN crystal for a mechanism based on melting, recrystallization and subsequent remelting. In the case of quenched samples, the melting temperatures are lower than those of homopolymers for compositions more than $40 \mathrm{wt} \%$ PBN. Generally, the melting temperature of a polymer blend is depressed due to morphological effects, such as size and perfection of crystals, and thermodynamic reason. The melting temperature depression for the blends with $40 \mathrm{wt} \% \mathrm{PBN}$ and $60 \mathrm{wt} \% \mathrm{PBN}$ is caused mainly by the morphological effects, because the blend which is immiscible or partially miscible does not show the depression of equilibrium melting point. However, for the blends containing more than $80 \mathrm{wt} \% \mathrm{PBN}$, the melting temperatures are depressed due to both of morphological effects and thermodynamic reason. In order to minimize morphological effects, the blend samples are crystallized isothermally and the melting temperatures are measured subsequently. For the blends con-

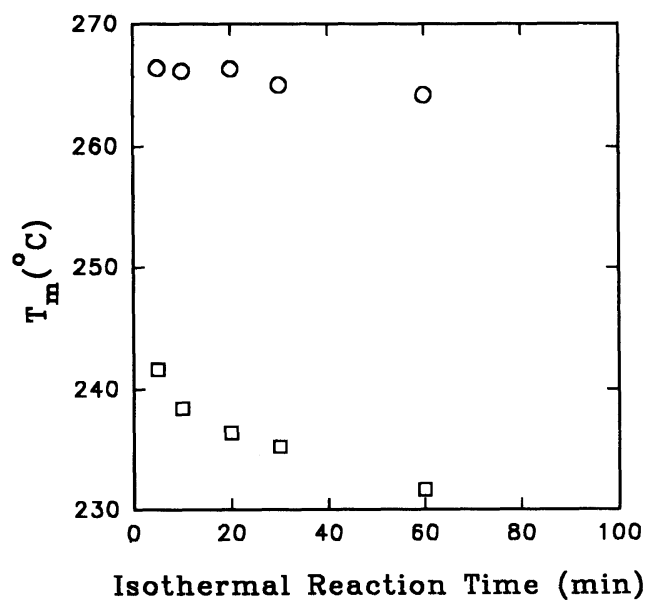

Figure 4. Changes of melting temperatures for PEN/ PBN blends with isothermal reaction time at $280^{\circ} \mathrm{C}$ : (O) PBN $10 \mathrm{wt} \%$; ( $\square$ ) PBN $90 \mathrm{wt} \%$.

taining less than $20 \mathrm{wt} \% \mathrm{PBN}$, the melting temperatures of isothermally crystallized samples, which are almost independent of blend composition, are slightly higher than those of quenched samples owing to crystal perfection and lamellar thickening. However, for the blends containing more than $40 \mathrm{wt} \% \mathrm{PBN}$, the melting temperature of isothermally crystallized samples are lower than those of quenched samples. This behavior suggests that an interchange reaction between PEN and PBN occurs during isothermal crystallization. It is well known that polyester blends can be transesterified at high temperatures and this reaction leads to the melting temperature depression owing to the copolymerization effect. In order to examine the dependence of melting temperature on the reaction time, samples were maintained at $280^{\circ} \mathrm{C}$ for different times, quenched into liquid nitrogen and heated at $300^{\circ} \mathrm{C}$ at $20^{\circ} \mathrm{C} \mathrm{min}^{-1}$. Using this dynamic program, the melting temperature-reaction time relationship was obtained as shown in Figure 4. The melting temperature of PEN crystal in the blend containing $10 \mathrm{wt} \% \mathrm{PBN}$, which is partially miscible, decreases slightly with reaction time. On the other hand, the large melting temperature depression is observed for 
the blend containing $90 \mathrm{wt} \% \mathrm{PBN}$, which is miscible. This behavior implies that transesterification occurs fast in miscible composition, compared to partially miscible one.

The non-isothermal exotherms observed on DSC curves in the cooling runs were analyzed by employing Ziabicki's theory. ${ }^{10,11}$ According to his theory, the kinetic crystallizability $G$ represents the degree of crystallinity over the entire crystallization range and is related to the maximum value of the rate constant $K_{\max }$ as follows:

$$
G=\left(\frac{\Pi}{\ln 2}\right)^{1 / 2} K_{\max }\left(\frac{D}{2}\right)
$$

where $D$ is the half width of DSC exothermic curve. The $K_{\max }$ value can be calculated by eq 2.

$$
K_{\max }=\frac{C_{\mathrm{k}}}{t_{\max }}
$$

Table II. Kinetic parameters characterizing the non-isothermal crystallization of

\begin{tabular}{|c|c|c|c|}
\hline PEN & $D$ & $K_{\max }$ & $G$ \\
\hline$w t \%$ & ${ }^{\circ} \mathrm{C}$ & $\min ^{-1}$ & ${ }^{\circ} \mathrm{Cmin}^{-1}$ \\
\hline 100 & 19.52 & 0.477 & 9.91 \\
\hline 95 & 20.15 & 0.563 & 12.08 \\
\hline 90 & 20.42 & 0.593 & 12.89 \\
\hline 85 & 20.95 & 0.613 & 13.67 \\
\hline 80 & 19.67 & 0.693 & 14.51 \\
\hline
\end{tabular}
PEN in PEN-rich blends

Table III. Kinetic parameters characterizing the non-isothermal crystallization of

\begin{tabular}{|c|c|c|c|}
\hline PBN & $D$ & $K_{\max }$ & $G$ \\
\hline wt $\%$ & ${ }^{\circ} \mathrm{C}$ & $\min ^{-1}$ & ${ }^{\circ} \mathrm{C} \min ^{-1}$ \\
\hline 100 & 5.962 & 2.171 & 13.78 \\
\hline 95 & 6.286 & 1.803 & 12.06 \\
\hline 90 & 6.571 & 1.631 & 11.41 \\
\hline 85 & 9.714 & 1.146 & 11.85 \\
\hline 80 & 10.057 & 1.144 & 12.25 \\
\hline
\end{tabular}
$\mathrm{PBN}$ in PBN-rich blends where $t_{\max }$ is the time from the start of crystallization to reaching the maximum rate of reaction, and $C_{\mathbf{k}}$ is the ratio of crystallinity before and after $t_{\max }$. Tables II and III list kinetic parameters characterizing the nonisothermal crystallization of PEN and PBN in blends, respectively. The larger value of $K_{\max }$ indicates that the polymer crystallizes more rapidly. $K_{\max }$ values are plotted against blend composition in Figures 5 and 6. The crystallization rate of PEN in PEN-rich blends increases with the increase of PBN content,

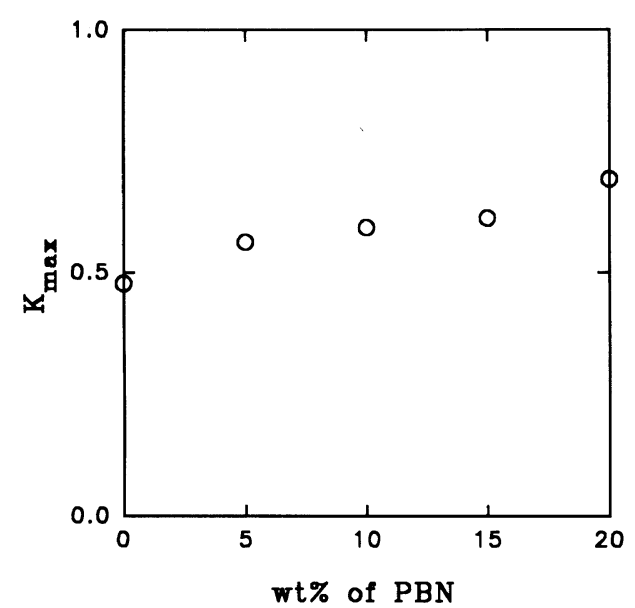

Figure 5. Maximum crystallization rate of $P E N$ in PEN-rich blends.

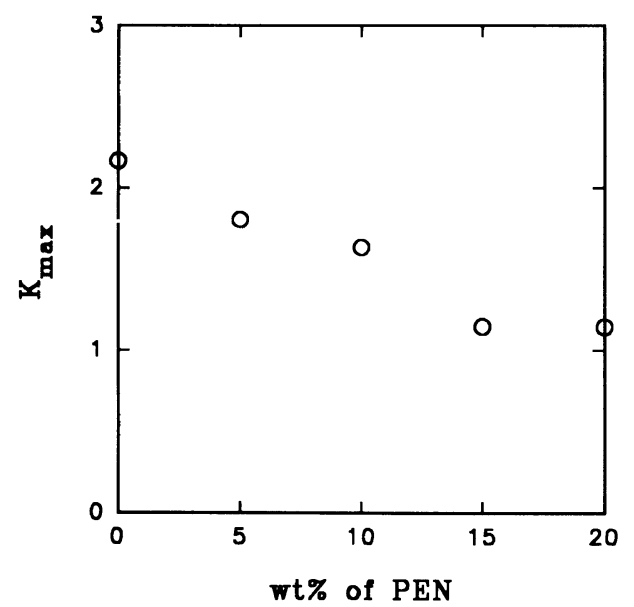

Figure 6. Maximum crystallization rate of $\mathrm{PBN}$ in PBN-rich blends. 
which is consistent with the result of the cold crystallization behavior in Figure 1, whereas that of PBN in PBN-rich blends decreases with the increase of PEN content. This can be explained by the general crystallization theory that the crystallization rate of a polymer decreases with addition of a higher $T_{\mathrm{g}}$ second component and vice versa. It is also observed that the $K_{\max }$ decrement of PBN crystallization against PEN content is larger than the $K_{\max }$ increment of PEN crystallization against PBN content, which is caused by the miscibility difference between PEN-rich blend and PBNrich one.

\section{CONCLUSIONS}

(1) The PEN/PBN blends containing more than $80 \mathrm{wt} \% \mathrm{PBN}$ form a single amorphous phase, whereas the blends for the other blend compositions seperate into PEN-rich and PBN-rich phases and the compositions of two phases vary with the blend composition.

(2) The melting behavior indicates that an interchange reaction between PEN and PBN occurs more rapidly in miscible composition, compared to partially miscible one.

(3) The crystallization of PEN is facilitated by adding PBN, while PEN hinders the crystallization of $\mathrm{PBN}$.
Acknowledgement. Author (K. H. Yoon) acknowledges the financial support provided by Korea Science \& Engineering Foundation in 1993.

\section{REFERENCES}

1. A. Escala and R. S. Stein, Adv. Chem. Ser., 176, 455 (1979).

2. Anon. Res. Disc., 283, 677 (1987).

3. M. Vesely and Z. Zamorsky, Plaste und Kautschuk, 3, 147 (1963).

4. D. R. Paul and J. W. Barlow, Polymer Blends: Introductory Overview and Future Development, in "Polymer Compatibility and Incompatibility," K. Solc, Ed., Harwood Academic Publishers, New York, N.Y., 1982.

5. D. C. Wahrmund, D. R. Paul, and J. W. Barlow, J. Appl. Polym. Sci., 22, 2155 (1979).

6. Z. G. Gardlund, Properties and Morphology of Poly(methyl methacrylate)/Bisphenol A Polycarbonate Blends, in "Polymer Blends and Composites in Multiphase System," C. D. Han, Ed., ACS, Washington, D.C., 1984.

7. W. N. Kim and C. M. Burns, J. Appl. Polym. Sci., 34, 945 (1987).

8. R. Koningsveld, L. A. Kleintjens, and H. M. Schoffeleers, Pure Appl. Chem., 39, 1 (1974).

9. R. Koningsveld, Discuss. Faraday Soc., 49, 144 (1970).

10. A. Ziabicki, "Fundamentals of Fiber Formation," John Wiley, New York, N.Y., (1976).

11. A. Jeziorny, Polymer, 19, 1142 (1978). 